\title{
A CLINICAL \& EPEDEMIOLOGICAL PROFILE OF LICHEN PLANUS AMONG CHILDREN
}

T. S. Mohan Rao ${ }^{1}$, P. Guru Prasad ${ }^{2}$, P. V. Krishnarao ${ }^{3}$, Shravya $^{4}$, T. Priyadarshini ${ }^{5}$, Sravanthi $^{6}$, Swapna $^{7}$, Divya $^{8}$

\section{HOW TO CITE THIS ARTICLE:}

T. S. Mohan Rao, P. Guru Prasad, P. V. Krishnarao, Shravya, T. Priyadarshini, Sravanthi, Swapna, Divya.

"A Clinical \& Epedemiological Profile of Lichen Planus among Children". Journal of Evolution of Medical and Dental Sciences 2015; Vol. 4, Issue 81, October 08; Page: 14152-14155, DOI: 10.14260/jemds/2015/2012

\begin{abstract}
Lichen planus (LP) is a common papulosquamous disorder of auto-immune Etiology characterised by pruritic, polygonal, purple, papules which was first described by Erasmus Wilson in 1869. LP affects all age groups and both sexes equally. Most cases have been reported in adult population but a few case series were present among children. This prompted us to carry-out the present study. MATERIALS \& METHODS: The present study was carried out for a period of 1year from April 2014 to April 2015 which includes a sample size of 20 patients $(n=20)$, attended to the dermatology OPD, Andhra Medical College, Visakhapatnam. Present study was done in children of less than 12 years of age including both sexes. Routine investigations such as hemogram, liver function test, and renal function test \& serological test have been done, detailed immunisation history has been recorded, detailed medical \& family history as well as drug history has been recorded. RESULTS: in our study the most common age group was in between 5 and 10 years. Among sex distribution male children were predominantly affected. Regarding the distribution of lesions lower limbs followed by trunk were the common sites to be effected, the most common morphological variants observed in our study were classical type followed by hypertrophic variant. CONCLUSION: our study concluded that the common age group was between 5 and 10 years and the most common presentation was classical type effecting the male children predominantly.
\end{abstract}

KEYWORDS: lichen planus, children, Classical type.

INTRODUCTION: Lichen planus was a common auto-immune, papulo-squamous dermatosis of unknown etiology. LP was first described by Erasmus Wilson in 1869 which was characterised by purple flat topped, polygonal, pruritic papular eruption affecting skin, mucous-membranes, nails \& hair.(1)

Lichen planus in children is considered to be rare overall, though it does not appear to be so in Indian subcontinent. Most of the last studies on lichen planus in children have been undertaken in India. ${ }^{(2)}$

The supposed rarity of childhood lichen planus could be due to the fact that its assosciations with auto-immune conditions, exposure to drugs \& dental restorative materials, infective agents (HBV,HCV,HHV-7) \& other environmental triggers that are uncommon in children.(1)

Mean age of onset of lichen planus has been 7-8 years. Males were found to be more commonly affected.(1)

Although lichen planus is usually sporadic, there is a familial form of lichen planus comprising $1-2 \%$ of all childhood cases of lichen planus.(3) Familial LP differs from classical form clinically, with earlier age at onset, more generalised involvement, more common mucosal involvement. There is an increased tendency for erosive \& ulcerative forms with prolonged course \& frequent relapse.(4) 


\section{ORIGINAL ARTICLE}

MATERIALS \& METHODS: The present Study was carried out for a period of 1year from April 2014 to April 2015. Present study includes a sample size of 20 patients $(\mathrm{N}=20)$, attended to the OPD of dermatology department, Andhra Medical College, Visakhapatnam. Present study was done in children of less than 12 years including both sexes. Routine investigations such as hemogram, liver function test, and renal function test \& serological test have been done. \& a detailed immunisation history has been recorded. \& a detailed medical, family history as well as drug history has been recorded.

RESULTS: In the present study the most common age group affected was 6-10 years of age accounting for $50 \%$ of cases. In the Present study LP was more common in male children (60\%). Lower limbs (80\%) were the commonest sites to be involved followed by trunk $(60 \%)$.Classical type $(80 \%)$ was most common followed by hypertrophic variant $(10 \%)$.

\section{DISCUSSION:}

- LP is considered to be rare in children.(5)

- In our study the common age was between 5-10 years which was in concurrence with a prior study done by handa \& sahoo.(6)

- Previous study done by kanwar et al.,(1) reported male preponderance which was in concordance with the present study where males accounting for $60 \%$.

- Classical lichen planus was the most common variant observed in most of the reports which was in concurrence with our study. $(1,6,7)$

- Lichen planus hypertrophicus was the second most common variant having an incidence of $12 \%$ has been reported, and in our study an incidence of LP hypertrophicus was $10 \% .{ }^{(1,7)}$

- A familial incidence of $15 \%$ was reported in our study in contrast to $1-2 \%$ observed by samman et al \& altmann et al.(3,8)

- Most common site of involvement observed in various studies, ${ }^{(1,6,7)}$ were lower limbs followed by trunk which were in concurrence with our observation

- Nail involvement is rare in children and an incidence of $1-10 \%$ was observed in adults. Different studies showed an incidence of $0-8.7 \% .(1,6,9)$ In our study nail involvement was not observed as described in the literature.

- Rarely scalp involvement was reported in children. In our study 1 case (5\%) was reported which was in concurrence with the observation of kanwar et al.,(1) which showed an incidence of $5 \%$.

- The special features observed in our study includes non-association with hepatitis-B vaccination.

- Other auto- immune cutaneous disorder such as alopecia areata was observed in 1 case.

CONCLUSION: our study concluded that the common age group was between 5 and 10 years and the characteristic lesions were of classical type, affecting the male children predominantly.

\section{REFERENCES:}

1. Kanwar AJ, De D. Lichen planus in children. Indian J Dermatol Venereol Leprol 2010; 76:366372. 


\section{ORIGINAL ARTICLE}

2. Kanwar AJ, Handa S, Ghosh S, Kuar S. Lichen planus in childhood: a report of 17 patients. pediatr Dermatol.1991;8:288-91.

3. Samman PD. Lichen planus: An analysis of 200 cases. Trans St Johns Hosp Dermatol Soc 1961; 46: 36-8. [PUBMED].

4. Katzenelson V, Lotem M, Sandbank M. Familial lichen planus. Dermatologica 1990; 180: 166-8.

5. Solomon LM, Ehrlich D, Zubkov B. Lichen planus and lichen nitidus. In: Harper J, Oranje A, Prose $\mathrm{N}$, editors. Textbook of Pediatric Dermatology. $2^{\text {nd }}$ Ed. Oxford UK: Blackwell Publishing 2006; p. 801-12.

6. Handa S, Sahoo B. Childhood lichen planus: A study of 87 cases. Int J Dermatol 2002; 41: 423- 7. [PUBMED] [FULLTEXT].

7. Sharma R, Maheshwari V. Childhood lichen planus: A report of fifty cases. Pediatr Dermatol 1999; 16: 345-8. [PUBMED] [FULLTEXT].

8. Altman J, Perry HO. The variations and course of lichen planus. Arch Dermatol 1961; 84: 17991. [PUBMED] [FULLTEXT].

9. Nanda A, Al- Ajmi HS, Al- Sabah H, Al- Hasawi F, Alsaleh QA. Childhood lichen planus: A report of 23 Cases. Pediatr Dermatol 2001; 18: 1-4.

\begin{tabular}{|c|c|c|}
\hline Age & Number & Percentage \\
\hline 1-5 years & 5 & $25 \%$ \\
\hline 6-10 years & 10 & $50 \%$ \\
\hline$>10$ years & 5 & $25 \%$ \\
\hline
\end{tabular}

Table 1: Age Distribution

\begin{tabular}{|c|c|c|}
\hline Age & Male & Female \\
\hline 1-5 years & $2(10 \%)$ & $3(15 \%)$ \\
\hline 6-10 years & $5(25 \%)$ & $5(25 \%)$ \\
\hline >10 years & $5(25 \%)$ & $0(30 \%)$ \\
\hline
\end{tabular}

Table 2: Sex Distribution

\begin{tabular}{|c|c|c|}
\hline Distribution of lesions & Male & Female \\
\hline Upper limb & $6(30 \%)$ & $2(10 \%)$ \\
\hline Lower limb & $11(55 \%)$ & $5(25 \%)$ \\
\hline Trunk & $7(35 \%)$ & $5(25 \%)$ \\
\hline Scalp & 0 & $2(10 \%)$ \\
Nails & 0 & 0 \\
\hline Mucosa & 0 & $1(5 \%)$ \\
\hline
\end{tabular}

Table 3: Distribution of Lesions

\begin{tabular}{|c|c|c|}
\hline Morphological Varients & Male & Female \\
\hline Classical & $10(50 \%)$ & $6(30 \%)$ \\
\hline Hypertrophic & $2(10 \%)$ & 0 \\
\hline Mucosal (Reticulate pattern) & 0 & $1(5 \%)$ \\
\hline \multicolumn{2}{|c|}{ Table 4: Morphological Variants } \\
\end{tabular}




\section{ORIGINAL ARTICLE}

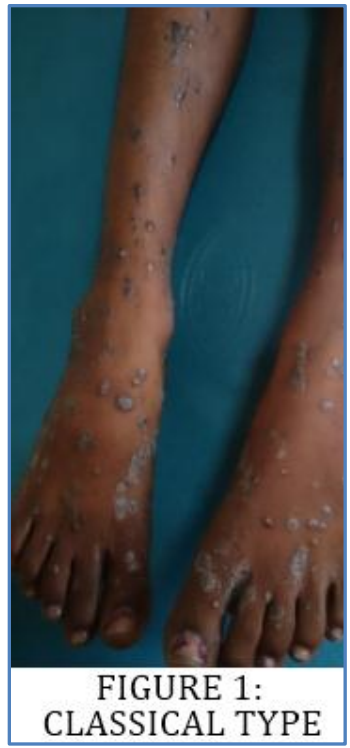

\section{AUTHORS:}

1. T. S. Mohan Rao

2. P. Guru Prasad

3. P. V. Krishnarao

4. Shravya

5. T. Priyadarshini

6. Sravanthi

7. Swapna

8. Divya

\section{PARTICULARS OF CONTRIBUTORS:}

1. Assistant Professor, Department of Dermatology, Andhra Medical College, Vishakhapatnam.

2. Associate Professor, Department of Dermatology, Andhra Medical College, Vishakhapatnam.

3. Assistant Professor and HOD, Department of Dermatology, Andhra Medical College, Vishakhapatnam.

4. Junior Resident, Department of Dermatology, Andhra Medical College, Vishakhapatnam.

\section{FINANCIAL OR OTHER} COMPETING INTERESTS: None

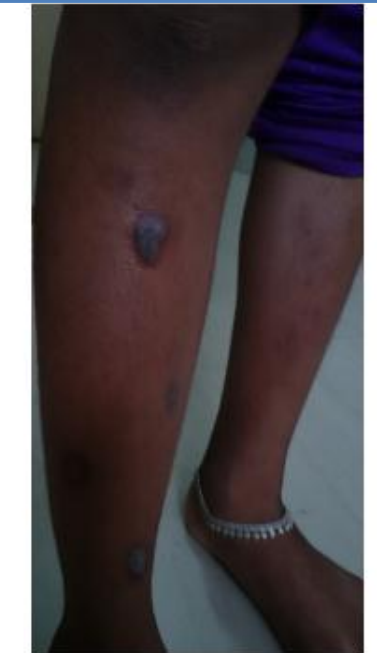

FIGURE 2:

HYPERTROPHIC TYPE

5. Senior Resident, Department of Dermatology, Andhra Medical College, Vishakhapatnam.

6. Senior Resident, Department of Dermatology, Andhra Medical College, Vishakhapatnam.

7. Senior Resident, Department of Dermatology, Andhra Medical College, Vishakhapatnam.

8. Senior Resident, Department of Dermatology, Andhra Medical College, Vishakhapatnam.

\section{NAME ADDRESS EMAIL ID OF THE CORRESPONDING AUTHOR:}

Dr. P. Guru Prasad,

Associate Professor,

Department of Dermatology,

Andhra Medical College,

Vishakhapatnam.

E-mail: gppatnala@yahoo.co.in

Date of Submission: 30/09/2015.

Date of Peer Review: 30/09/2015.

Date of Acceptance: 01/10/2015.

Date of Publishing: 07/10/2015. 